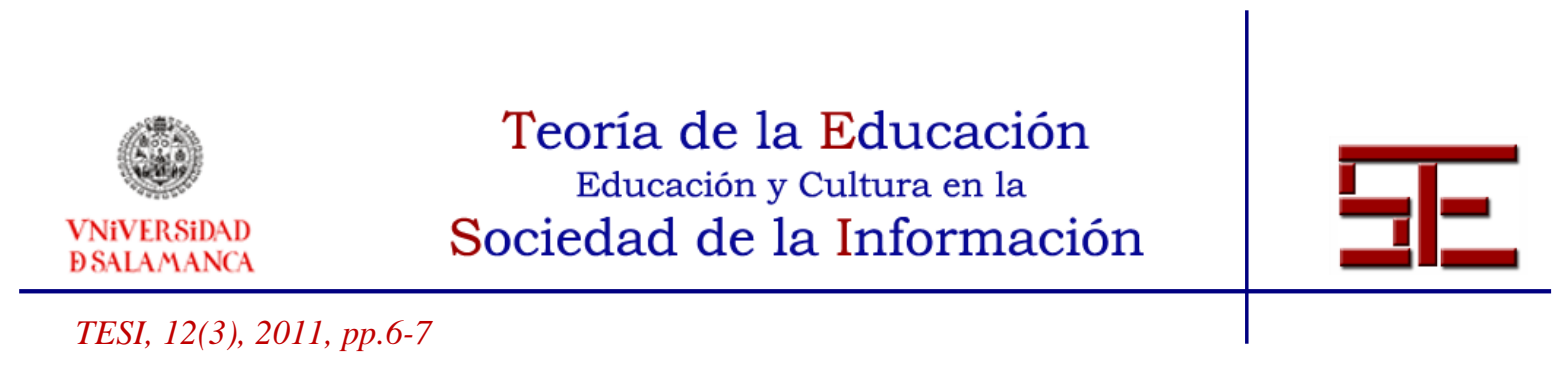

Dr. Jesús García Laborda

jesus.garcialaborda@uah.es

Universidad de Alcalá

Dra. Ana Halbach

ana.halbach@uah.es

Universidad de Alcalá

\title{
Sociedad de la Información, lenguas minoritarias y educación en bilingüismo.
}

El concepto de lengua minoritaria es casi tan difícil de definir como el de educación bilingüe. Cuando nos planteamos este número de la revista Teoría de la Educación "Educación y Cultura en la Sociedad de la Información" bien sabíamos que era un tema sugerente y que presentaría una gran diversidad temática y situacional. La Era de la Información que nos ha tocado vivir vive desde la década de los 80 del pasado siglo el efecto más brutal de la globalización. Por un lado hemos visto como las lenguas minoritarias tienen que luchar y solamente connotaciones de cariz político han permitido, afortunadamente, su supervivencia. De hecho, parecemos caminar hacia una aparente simplificación lingüística en la que las lenguas francas parecen haber tomado tal fuerza que los esfuerzo educativos de muchas naciones parecen ir más dedicados al aprendizaje de esas lenguas internacionales que al desarrollo equilibrado de las mismas con las lenguas en contacto. No olvidemos que la riqueza linguiística es un don con profundos efectos en las economías nacionales e internacionales. Limitar a los estudiantes a través de la creación de situaciones diastráticas en entornos que ya son potencialmente ricos por la existencia de dos o varias lenguas no lleva sino al empobrecimiento lingüístico creciente de los hablantes cuando, en realidad, la promoción equilibrada de las lenguas y la educación bilingüe han demostrado su gran importancia y su valor en la construcción de la cultura, la riqueza y, en resumidas

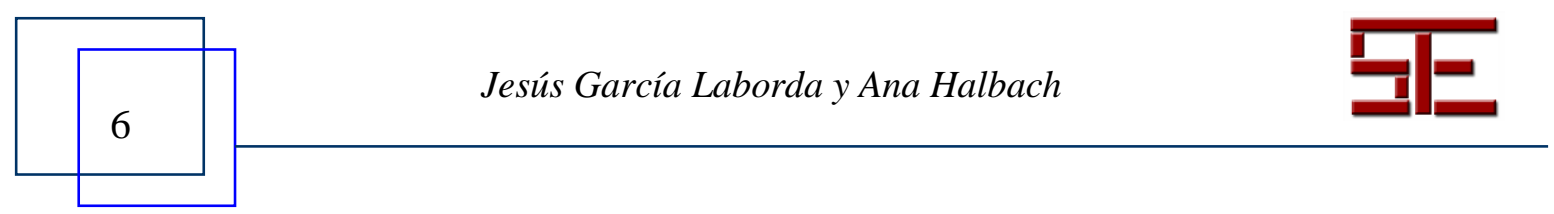




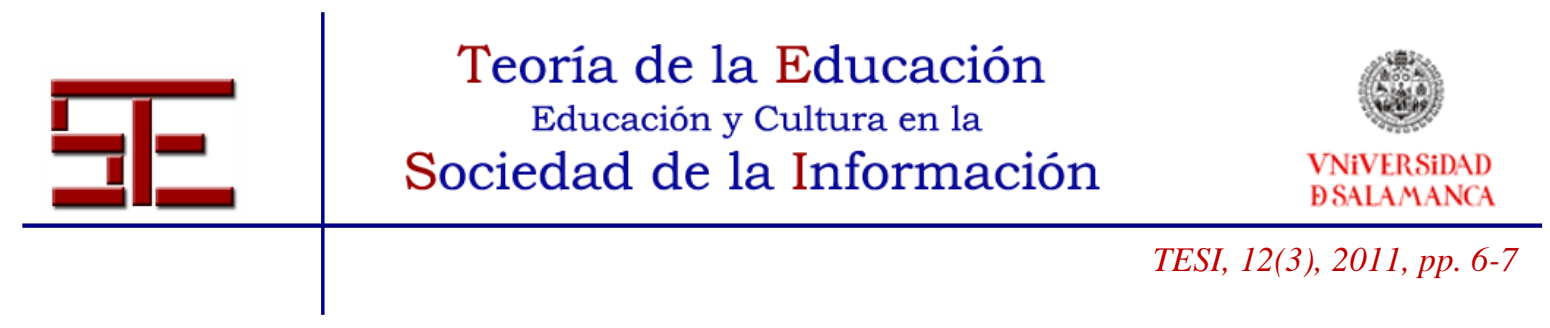

cuentas, el crecimiento del individuo. Ejemplos inequívocos de nuestras palabras son los casos del distrito de D'Alambert en Quebec (en el sentido positivo) o el "Only English Movement" (en el sentido negativo) (García Laborda, 1999) ${ }^{1}$ deberían hacer pensar a nuestras autoridades en España y el mundo entero en cómo y qué son lenguas minoritarias y en la importancia del crecimiento multilingüe equilibrado.

Los artículos que presentamos en este monográfico son ejemplos de buenas prácticas y muestra de la preocupación entre los investigadores. Así el fenómeno bi/multilingüe aparece tanto en los Estados Unidos como España como prácticamente en todo el mundo. Es evidente la necesidad de revisar los aspectos que situaciones multiculturales aportan en el léxico, en la formación del profesorado y, en definitiva, en una gran variedad de entornos. Como la mayor parte de los autores, nos acogemos a los beneficios que la moderación en las políticas multilingües pueden traer a cada situación y contexto. Probablemente el lector echará de menos el tratamiento de ciertos aspectos relacionado con el tema del número pero también tenemos la esperanza de que este número sea acicate para ampliar perspectivas y desarrolle un genuino deseo de lecturas posteriores. Finalmente, no nos queda más que hacer una cordial invitación al lector de la revista a recrearse en este monográfico que tanto hemos disfrutado los autores como nosotros mismos a la hora de leer sus valiosas y bien fundamentadas contribuciones.

${ }^{1}$ García Laborda, J. (1999). Establishing validity in minority language education: does the Canadian bilingual education cope with aboriginals' needs? En Visions of Canada approaching the millennium, Madrid: Universidad Autónoma, 103-110.

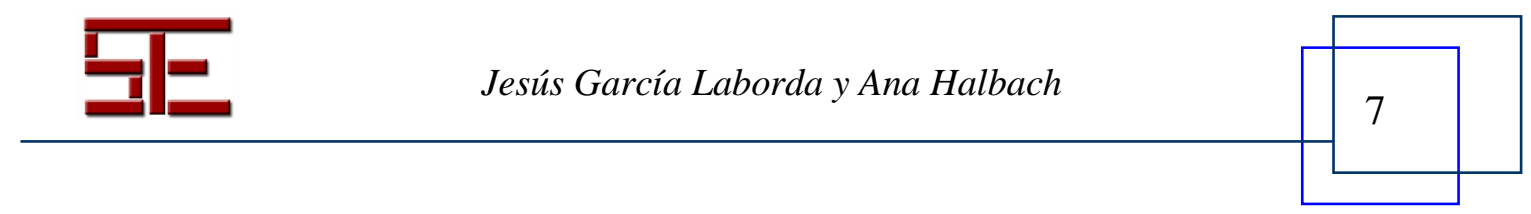

